\title{
Orbitofrontal Cortex and Drug Use During Adolescence
}

\section{Role of Prenatal Exposure to Maternal Smoking and BDNF Genotype}

\author{
Shahrdad Lotfipour, PhD; Eamonn Ferguson, PhD; Gabriel Leonard, PhD; Michel Perron, PhD; \\ Bruce Pike, PhD; Louis Richer, PhD; Jean R. Séguin, PhD; Roberto Toro, PhD; \\ Suzanne Veillette, PhD; Zdenka Pausova, MD; Tomáš Paus, MD, PhD
}

\begin{abstract}
Confext: Prenatal exposure to maternal cigarette smoking (PEMCS) may affect brain development and behavior in adolescent offspring.
\end{abstract}

Objective: To evaluate the involvement of the orbitofrontal cortex (OFC) in mediating the relationship between PEMCS and substance use.

Design: Cross-sectional analyses from the Saguenay Youth Study aimed at evaluating the effects of PEMCS on brain development and behavior among adolescents. Nonexposed adolescents were matched with adolescents exposed prenatally to cigarette smoking by maternal educational level.

Participants and Setting: A French Canadian founder population of the Saguenay-Lac-Saint-Jean region of Quebec, Canada. The behavioral data set included 597 adolescents (275 sibships; $12-18$ years of age), half of whom were exposed in utero to maternal cigarette smoking. Analysis of cortical thickness and genotyping were performed using available data from 314 adolescents.
Main Oufcome Measures: The likelihood of substance use was assessed with the Diagnostic Interview Schedule for Children Predictive Scales. The number of different drugs tried by each adolescent was assessed using another questionnaire. Thickness of the OFC was estimated from $\mathrm{Tl}$-weighted magnetic resonance images using FreeSurfer software.

Results: Prenatal exposure to maternal cigarette smoking is associated with an increased likelihood of substance use. Among exposed adolescents, the likelihood of drug experimentation correlates with the degree of OFC thinning. In nonexposed adolescents, the thickness of the OFC increases as a function of the number of drugs tried. The latter effect is moderated by a brain-derived neurotrophic factor (BDNF) genotype (Val66Met).

Conclusions: We speculate that PEMCS interferes with the development of the OFC and, in turn, increases the likelihood of drug use among adolescents. In contrast, we suggest that, among nonexposed adolescents, drug experimentation influences the OFC thickness via processes akin to experience-induced plasticity.

Arch Gen Psychiatry. 2009;66(11):1244-1252
Author Affiliations: Brain and Body Centre (Drs Lotfipour, Toro, Pausova, and Paus) and School of Psychology (Dr Ferguson), University of Nottingham, United Kingdom; Montréal Neurological Institute, McGill University

(Drs Leonard, Pike, and Paus), and Hospital Centre of the University of Montreal (Drs Perron, Veillette, and Pausova), and Department of Psychiatry (Dr Séguin) and University of Montreal, Montreal, Quebec, Canada; Department of Psychology, University of Quebec in Chicoutimi, Chicoutimi, Quebec (Dr Richer); and Cégep de Jonquière, Jonquiere, Quebec (Drs Perron and Veillette).

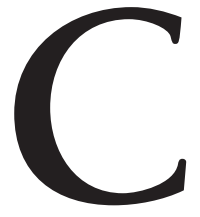

IGARETTE SMOKING DURing pregnancy is not uncommon; $16 \%$ to $60 \%$ of pregnant women smoke, with the prevalence varying across countries and socioeconomic groups. Smoking during pregnancy is associated with several adverse outcomes among offspring. The most severe appear during early development and at birth, including spontaneous abortion, smaller birth weight, and sudden infant death syndrome. ${ }^{1}$ Growing evidence also indicates increased rates of behavioral problems among offspring exposed in utero to maternal cigarette smoking. ${ }^{2,3}$

One significant behavioral problem associated with prenatal exposure to maternal cigarette smoking (PEMCS) is the increased rate of experimentation with drugs of abuse in childhood, adolescence, and adulthood. ${ }^{4}$ This association might be mediated by a direct effect of prenatal exposure to nicotine, the major psychoactive compound in cigarettes, on reward-related neural circuitry. Acting on neuronal nicotinic receptors, nicotine modulates the release of neurotransmitters and neuropeptides associated with drug reward. ${ }^{5}$ Based on a number of experiments in animals, it has been suggested that chronic exposure to nicotine during prenatal development influences the reward circuitry and, in turn, modifies the psychoactive effects of drugs later in life. ${ }^{6}$

High-affinity nicotinic receptors are present in the human orbitofrontal cortex (OFC) and increase in number after smoking. ${ }^{7}$ We have recently demon- 
strated that PEMCS is associated with thinning of the human OFC among adolescent offspring. ${ }^{8}$ It has been hypothesized that changes in the function and/or structure of the OFC could lead to an increase in substance use. ${ }^{9,10}$ In humans, adults with drug addiction have OFCs of smaller volume. ${ }^{11}$ Animal experiments have demonstrated that OFC lesions lead to alterations in cue-mediated drug intake, stimulus-reinforcement behavior, and impulsive behavior. ${ }^{10,12}$ Human functional imaging studies suggest that the OFC is sensitive to drug-associated stimuli rather than the drug itself. ${ }^{13}$ This is consistent with studies in nonhuman primates, which demonstrate that neuronal activity in the OFC increases in response to cues predicting reward stimuli. ${ }^{14}$ Thus, it appears that the OFC is important for the processing of cues associated with rewards and for the control of impulsive behavior. It is, therefore, likely that structural and/or functional properties of the OFC predict drug experimentation. This may be particularly true when drug-taking behavior emerges, namely, during adolescence.

In this study, we tested this hypothesis by studying the relationship between OFC thickness and drug experimentation in a population-based sample of adolescents (12-18 years of age), half of whom had been exposed to maternal cigarette smoking during gestation, matched to nonexposed adolescents by maternal educational level.

\section{METHODS}

This work reports findings of the ongoing Saguenay Youth Study, aimed at evaluating the effects of PEMCS on brain development and behavior as well as cardiovascular and metabolic health among adolescent offspring. ${ }^{15}$ The Research Ethics Committee of the Chicoutimi Hospital approved the study protocol.

\section{PARTICIPANTS}

Adolescents and their biological parents were recruited from a founder population of the Saguenay-Lac-Saint-Jean region of Quebec. Both maternal and paternal grandparents of the adolescents were of French Canadian ancestry born in the region; as such, all adolescents are of a single ethnicity, namely, whites of French Canadian ancestry. The Saguenay Youth Study uses a family-based design in which only children with 1 or more siblings and both biological parents are included. This design was used to allow for linkage-based genetic analyses rather than to select siblings discordant for PEMCS; we found that such discordance is low (27 of 275 sibships [9.8\%] in the current sample). The current behavioral data set included 597 adolescents from 275 sibships. Demographic characteristics for the sample are reported in eTable 1 (available at http:// www.archgenpsychiatry.com). Analysis of cortical thickness and genotyping were performed on available data from 314 adolescents in 138 sibships. Demographic characteristics for these 314 participants did not differ from those of the larger sample size used in our behavioral data set (eTable 2).

\section{RECRUITMENT}

Adolescents were recruited as previously reported. ${ }^{15}$ Briefly, recruitment begins with the research team visiting all class- rooms in a given secondary school and presenting the study to the students. Concurrently, a brochure, a letter from the principal, and a consent form for a telephone interview are mailed to parents. Subsequently, a research nurse conducts a telephone interview with interested families, usually with the adolescent's biological mother, to verify eligibility. Additional information is acquired using a medical questionnaire completed by the child's biological parent.

The main exclusion criteria for exposed and nonexposed adolescents are: history of meningitis, malignant tumor, or heart disease requiring surgical treatment; severe mental illness (eg, autism, schizophrenia) or mental retardation (IQ $<70$ ); premature birth (gestational age $<35$ weeks); and contraindications to magnetic resonance imaging. The following inclusion criteria are used for exposed and nonexposed adolescents: 12 to 18 years of age; 1 or more siblings in the same age group; and maternal and paternal grandparents of French Canadian ancestry. Exposed adolescents must have a history of maternal cigarette smoking ( $>1$ cigarette per day in the second trimester of pregnancy). Nonexposed adolescents are matched to exposed adolescents based on maternal educational level and school attended. For mothers of nonexposed offspring, we require a negative history of cigarette smoking during pregnancy and during the 12-month period preceding pregnancy. Mothers of exposed and nonexposed adolescents should have a negative history of excessive alcohol use during pregnancy $(>210 \mathrm{~mL} / \mathrm{wk})$. Cigarette smoking status before and during pregnancy is ascertained retrospectively by a research nurse during a structured telephone interview with the adolescent's mother. We assessed the overall agreement between exposure status noted in the medical records during pregnancy and maternal report during the telephone interview using a $\kappa$ statistic and found a mean (SD) value of $0.69(0.04)$, indicating a good agreement. ${ }^{15}$

\section{MAGNETIC RESONANCE IMAGING}

Magnetic resonance imaging data were collected as reported previously. ${ }^{15}$ Briefly, magnetic resonance images were acquired on a Philips 1.0-T superconducting magnet (Gyroscan NT; Philips Medical Systems, Best, the Netherlands). High-resolution anatomical T1-weighted images were acquired using the following parameters: 3-dimensional radio frequency-spoiled gradient echo scan with 140 to 160 sagittal slices, 1-mm isotropic resolution, a 25-millisecond repetition time, a 5-millisecond echo time, and a $30^{\circ}$ flip angle. We measured cortical thickness using FreeSurfer, a set of automated tools for reconstruction of the brain cortical surface. ${ }^{16}$ For every participant, FreeSurfer segments the cerebral cortex, the white matter, and other subcortical structures and then computes approximately 160000 triangular meshes that recover the geometric and topological characteristics of the pial surface and the gray/white matter interface of the left and right hemispheres. Local cortical thickness is measured based on the difference between the position of equivalent vertices in the pial and gray/white matter surfaces. A correspondence between cortical surfaces across participants is established using a nonlinear alignment of the principal sulci in each participant's brain with a reference brain. ${ }^{17}$ In FreeSurfer, what we describe in this study as the OFC is classified by the software as the lateral OFC, as previously defined. ${ }^{17}$ Based on the anatomical parcellation of the OFC by Chiavaras et al, ${ }^{18}$ we defined the OFC as including the anterior, medial, and posterior OFC but excluding the adjacent gyrus rectus (defined by FreeSurfer as the medial OFC) and the lateral orbital gyrus (defined by FreeSurfer as the pars orbitalis). The latter 2 
FreeSurfer-based segments extend beyond the OFC onto other frontal areas on the medial and lateral convexity.

\section{GENOTYPING}

A single-nucleotide polymorphism in the brain-derived neurotrophic factor (BDNF) gene (rs6265; G/A) with the minor A allele was genotyped using the KASPar system (KBiosciences, Hoddesdon, England). KASPar is a competitive allele-specific polymerase chain reaction-based single-nucleotide polymorphism genotyping system that uses fluorescence resonance energy transfer quencher cassette oligonucleotides. Quality of genotyping was assured by validating the assay with an in-house panel consisting of 44 samples from white participants, with all genotypes falling within the Hardy-Weinberg equilibrium. In addition, all DNA samples were tested with 2 in-house qualitycontrol assays to guarantee the high quality of genomic DNA. Finally, 2 different KBiosciences personnel independently scored all genotypes. The rs6265 genotype distribution in the Saguenay Youth Study cohort (Val/Val: GG, 66.1\%; Val/Met: GA, 28.4\%; Met/Met: AA, 5.5\%; $\mathrm{n}=310$ ) was similar to that reported in other population-based cohorts. ${ }^{19}$ Moreover, allele frequencies did not differ between exposed and nonexposed groups. Of 314 adolescents genotyped, 4 (1.3\%) were excluded because of missing genotype values.

\section{PSYCHIATRIC SYMPTOMS AND SUBSTANCE USE}

\section{Adolescents}

The likelihood of psychiatric diagnosis was assessed using the Diagnostic Interview Schedule for Children Predictive Scales (DPS), ${ }^{20}$ a "brief diagnostic-specific self-report inventory that identifies youths endorsing symptoms and who are highly likely to meet diagnosis criteria."21(p833) The scale has previously been validated against the Diagnostic Interview Schedule for Children ${ }^{20}$ and Voice-Diagnostic Interview Schedule for Children. ${ }^{21}$

In the DPS, 15 questions concern the use of and problems associated with alcohol (4 questions), marijuana (3 questions), and other substances (8 questions). We combined the 3 types of substances into a single cluster, named substance use, as in previous studies. ${ }^{20,21}$ The sum of all positive answers (maximum score, 15) was used as the main outcome variable in the analysis of the effect of PEMCS on substance use. For the total sample $(n=597)$, scores on the 15-item DPS scale ranged from 0 to 13 (mean [SD], 1.16 [1.84]). For the MRI sample $(n=314)$, DPS scores ranged from 0 to 13 (mean [SD], 1.25 [1.89]). In addition to the substance use score, we also calculated a composite measure of all current adolescent psychiatric symptoms, excluding substance use.

To provide an index of drug exposure complementary to DPS, we also collected information about adolescent drug experimentation by asking 15 questions about the use of alcohol, cigarettes, marijuana, and other illicit drugs, namely, stimulants, psychedelics, PCP, Ecstasy, prescription drugs, inhalers, cocaine, opiates, tranquilizers, heroin, anabolic steroids, and other drugs not listed (eAppendix); these questions had been used previously ${ }^{22}$ and, for this study, were incorporated in the GRIPado (Groupe de recherche sur l'inadaptation psychosociale chez l'enfant [Research Unit on Children's Psychosocial Maladjustment] adolescent) questionnaire. The outcome measure was the sum of positive answers to the 15 questions regarding lifetime history of drug use. Mean (SD) scores on the 15-item GRIPado scale were 1.56 (1.87) (range, 0-11) for the total sample $(\mathrm{n}=597)$ and $1.70(1.87)$ (range, $0-11)$ for the MRI sample $(n=314)$. There was a strong correlation between the DPS and GRIPado scales (total sample: $r^{2}=0.63, P<.001$; and MRI sample: $\left.r^{2}=0.57, P<.001\right)$.

We also assessed drug use by peers, as reported by the target adolescent, which was included in the Positive Youth Development questionnaire, ${ }^{23}$ a composite measure of friends who smoked, drank, or did drugs. Finally, current parental monitoring and level of warmth were assessed by the adolescent and included in the Positive Youth Development questionnaire.

\section{Parents}

We assessed frequency of current symptoms of depression and anxiety of the biological father and mother. ${ }^{24}$ Parental assessments of cigarette, alcohol, and drug use were based on the National Survey on the Health of the Population and developed by the project team of the Saguenay Youth Study..$^{15}$ Finally, the assessment of parental antisocial behavior during adolescence and adulthood was based on that of Zoccolillo et al. ${ }^{22}$

\section{OTHER VARIABLES}

Adolescents' general intelligence was assessed with the Wechsler Intelligence Scale for Children. Self-attributes were also assessed through the questionnaire on resistance to peer influence. ${ }^{25}$ Data on pregnancy, birth, and the early postnatal period were obtained through a structured interview with the biological mother and a medical questionnaire administered to a biological parent; duration of pregnancy, use of alcohol and drugs during pregnancy, birth weight, and breastfeeding data were acquired as previously described. ${ }^{15}$ Socioeconomic variables included parental educational levels and household income as well as several additional measures such as perception of financial difficulties. ${ }^{15}$

\section{STATISTICAL ANALYSIS}

\section{Behavioral Data}

Statistical analysis of behavioral data was performed using hierarchical linear modeling (HLM statistical software, version 6.0; Scientific Software International, Lincolnwood, Illinois). Using HLM, we could account for the clustering of sibling pairs within families. This procedure allowed us to determine the relationship of the offspring and family predictors with the main outcome variable, namely, the total score on the DPS-based substanceuse cluster. This technique ensures that the appropriate estimates of standard errors are calculated.$^{26}$ Within HLM, parental data are specified as a level 2 variable, which estimates between-family effects, and the sibling data as a level 1 variable, which models withinfamily variability. This structure allows one to model how familylevel variables influence sibling-level variables and to calculate the correct error terms, as well as to take into account the interdependence within a family and examine the influence of the single-parent estimates of socioeconomic status or antisocial behavior on each of the sibling scores without double or triple counting, leading to pseudoreplication, as would be the case in standard regression.

Because the distribution of the outcome variable was highly skewed, we transformed the data using Poisson distribution. ${ }^{26}$ We then identified possible offspring-based confounders of PEMCS, such as breastfeeding, or parent-based predictors of substance use, such as parental antisocial behavior, and included these in the multivariate analyses carried out with HLM. To ensure numerical stability for HLM analysis and its inter- 


\begin{tabular}{|c|c|c|c|}
\hline Variable Name & $\begin{array}{l}\text { Standardized } \\
\text { Coefficient }^{\mathrm{a}}\end{array}$ & T Ratio & $P$ Value \\
\hline \multicolumn{4}{|c|}{ Total Sample $(n=597 ; d f=457)$} \\
\hline Prenatal exposure to maternal cigarette smoking & 0.10 & 2.592 & .01 \\
\hline Age, mo & 0.21 & 4.366 & $<.001$ \\
\hline Friends smoke, drink, and do drugs & 0.43 & 4.147 & $<.001$ \\
\hline Adolescent psychiatric symptoms & 0.20 & 3.291 & .001 \\
\hline \multicolumn{4}{|c|}{ Genotyping Sample $(n=314 ; d f=269)$} \\
\hline Prenatal exposure to maternal cigarette smoking & 0.12 & 2.820 & .006 \\
\hline Age, mo & 0.13 & 2.504 & .01 \\
\hline Friends smoke, drink, and do drugs & 0.39 & 3.002 & .003 \\
\hline Adolescent psychiatric symptoms & 0.22 & 3.393 & .001 \\
\hline
\end{tabular}

a The formulas for calculating the standardized coefficients can be found in Hox. ${ }^{27}$

pretation, each of the offspring and parental predictor variables was evaluated for collinearity and for the selection of the correct location of their respective intercepts. ${ }^{26}$

We built our predictor models using theoretical and empirical considerations, as addressed in the book by Raudenbush and Bryk. ${ }^{26}$ We used a "step-up" strategy of building up from a univariate to a multivariate model. To determine which predictors should remain in the model and which should be omitted, we added variables individually and tested the linearity of the predictor variable with that of the outcome variable. ${ }^{26}$ Only the predictor variables that illustrated significance $(P<.05)$ of the associated coefficients were retained in the final model. Once the offspring-based model was determined, we added parental variables to the model. The approach to model building for parental predictors was similar to that described for the offspring predictors. We divided conceptually our parental predictors into "distinct subsets and fitted the submodel for each." $26($ p267) At the end of our analysis, no parental predictors remained significant. Moreover, because data were missing for some variables, a small number of participants, with equal distribution in the exposed and nonexposed groups, were excluded from the final analysis (Table). The final formula for the remaining significant offspring predictors is shown below:

Log[Sum of Scores on Full-Scale DPS Substance Use Disorder Questions] $=\mathrm{B} 0+\mathrm{B} 1 \times($ Exposure $)+$

B2 $\times$ (Friends Smoking, Drinking, and Doing Drugs)

$+\mathrm{B} 3 \times($ Age in Months $)+\mathrm{B} 4 \times($ Full DPS-Rated Psychiatric Symptoms),

in which B0 is the intercept of the equation, and B1 through $\mathrm{B} 4$ represent the slope of the indicator variables. Predictors in boldface type represent group-mean centered variables.

\section{CORTICAL THICKNESS}

Analysis of cortical thickness was performed using data from 314 adolescents. Data evaluating the associations between genotype, behavior, and cortical thickness used a linear model that included the main effects as well as their interactions (JMP statistical software, version 5.1.2, SAS Institute Inc, Cary, North Carolina). Given the known age and sex effects on cortical thickness, ${ }^{8}$ and those observed in our current sample, we used ageand sex-corrected OFC thickness values in our analyses. Of 314 participants in the initial sample, 8 (2.5\%) were excluded because of missing values relating to drug use, 4 (1.3\%) for missing genotype data, and $1(0.3 \%)$ for missing both drug intake and genotyping data (final sample size, $\mathrm{n}=303$ ).
RESULTS

\section{ADOLESCENT SUBSTANCE USE}

Our findings revealed that PEMCS is associated with a 1.5-fold increase in substance use $(P=.01)$ (Table). Other factors predicting substance use included adolescent's age, peer drug use, and adolescent psychiatric symptoms $(P \leq .001)$ (Table). Sex and sex $\times$ exposure were not significant predictors of DPS substance use scores. These findings illustrate that PEMCS is associated with an increase in substance use among adolescents, even after controlling for other variables such as age and peer drug use. Inclusion of potential confounders, such as birth weight, breastfeeding, mother's alcohol use during pregnancy, and parental history of antisocial behavior during adolescence and adulthood, did not alter these results.

\section{CORTICAL THICKNESS AND DRUG USE}

Several lines of evidence point to the possible involvement of the OFC in influencing substance use behavior. Therefore, we tested the hypothesis that the thickness of the OFC is associated with the number of different drugs tried by adolescents in their lifetime, as assessed by the GRIPado. Cortical thickness was evaluated in a subset of 314 participants for whom measures of cortical thickness were available at the time of analysis. This group had demographic characteristics nearly identical to the larger behavioral sample (eTables 1 and 2 ). We observed a main effect for PEMCS $\left(F_{3,302}=11.3 ; P<.001\right)$, as reported previously, ${ }^{8}$ but no main effect for the number of drugs tried $\left(F_{3,302}=0.09 ; P=.76\right)$. More important, we observed a 2-way interaction between the effect of PEMCS and the number of drugs tried by the adolescent on OFC thickness $\left(F_{3,302}=18.6 ; P<.001\right)$. As predicted, among 150 exposed adolescents, more drug experimentation was associated with a thinner OFC $\left(R^{2}=0.08\right.$; $P<.001$ ) (Figure). Among 156 nonexposed adolescents, however, trying more types of drugs was associated with a thicker OFC $\left(R^{2}=0.05 ; P=.007\right)$ (Figure). We propose that the association between $\mathrm{OFC}$ thickness and drug experimentation among nonexposed adolescents rep- 
A
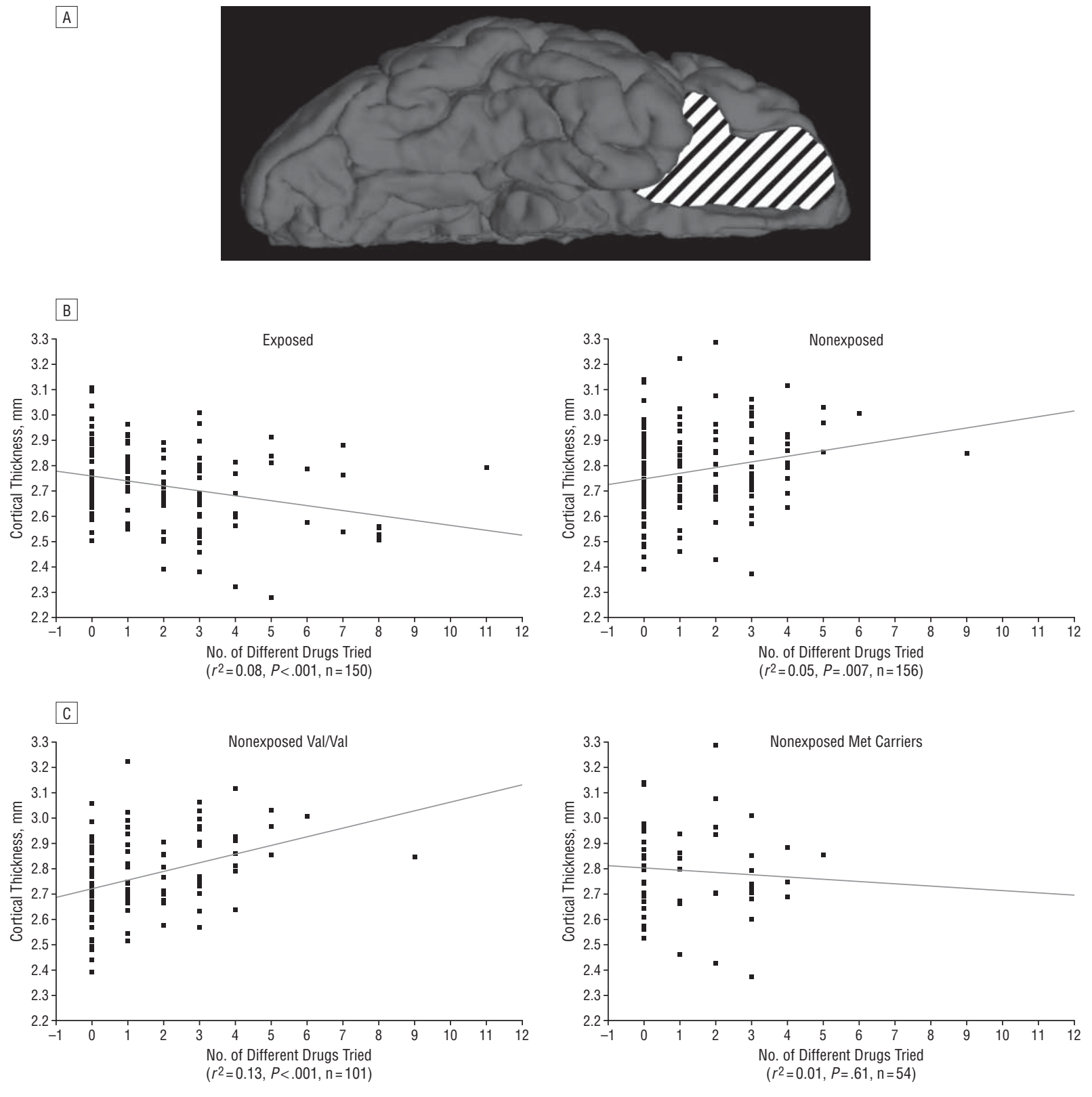

Figure. The orbitofrontal cortex (OFC) in the human brain (shaded area) (A). Group differences in the relationship between the thickness of the OFC and drug experimentation. B, Adolescents exposed or not exposed to maternal cigarette smoking during pregnancy exhibit a correlation between the number of different drugs tried in their lifetime and the cortical thickness of the OFC. Among exposed adolescents, the degree of OFC thinning is associated with an increase in the number of drugs tried. Among nonexposed adolescents, the increase in the number of drugs tried is associated with thickening of the OFC. Note that removing the single outlier in the exposed and nonexposed groups, respectively, did not change the fit substantially (exposed, $r^{2}=0.10$; nonexposed, $r^{2}=0.05$ ). C, Orbitofrontal cortex thickness and BDNF genotype. The thickening of the OFC as a function of the number of drugs tried was only present in nonexposed adolescents with the efficient Val/Val BDNF genotype (left) and not the Met-carrier genotype (right). Among adolescents exposed to maternal cigarette smoking, the negative correlation between OFC thinning and number of drugs tried did not significantly differ depending on the individual $B D N F$ genotype $\left(F_{3,146}=0.65 ; P=.42\right)$. Note that removing the single outlier in the Val/Val group did not change the fit substantially $\left(r^{2}=0.15\right)$.

resents a form of experience-induced plasticity. This possibility was explored next using the Val66Met functional polymorphism in the BDNF gene, which is known to influence activity-dependent release of BDNF and, in turn, brain structure.

We found a significant 3-way interaction among BDNF genotype, PEMCS, and the number of drugs tried in predicting OFC thickness $\left(F_{7,302}=5.68 ; P=.02\right)$; there was no main effect of BDNF genotype $\left(F_{7,302}=0.03 ; P=.86\right)$.
Among nonexposed adolescents, the BDNF genotype interacted with the number of drugs tried $\left(F_{3,151}=5.76\right.$; $P=.02$ ) (Figure); this was not the case among exposed adolescents $\left(F_{3,146}=0.65 ; P=.42\right)$. As predicted, among nonexposed adolescents only, those with the Val/Val genotype $(\mathrm{n}=101)$ demonstrated a significant positive correlation between OFC thickness and the number of drugs tried $\left(R^{2}=0.13 ; P<.001\right)$ (Figure). Among Met carriers (ie, 54 individuals with the less efficient BDNF geno- 
type) no such correlation was observed $\left(R^{2}=0.01 ; P=.61\right)$. These findings provide support for the hypothesis that, among adolescents not exposed to maternal smoking during pregnancy, OFC thickness is being modified by activity-dependent release of BDNF presumably associated with drug-related behavior.

\section{COMMENT}

Our current findings demonstrate that PEMCS is associated with a greater likelihood of drug experimentation during adolescence; the thinner the OFC, the more different drugs had been tried by exposed adolescents; and the more drugs tried by nonexposed adolescents, the thicker the OFC — an effect moderated by the BDNF genotype. We speculate that PEMCS interferes with the development of the OFC and, in turn, increases the likelihood of drug use among adolescents. We further suggest that, among nonexposed adolescents, drug experimentation influences $\mathrm{OFC}$ thickness via processes akin to experience-induced plasticity.

\section{INFLUENCES OF PEMCS ON BRAIN STRUCTURE}

In humans, several recent studies have reported an association between PEMCS and brain structure later in life. We have shown that PEMCS is associated with less thickness of the cerebral cortex in adolescents. ${ }^{8}$ Others have found associations between PEMCS and regional volumes of cortical gray matter during early adolescence, ${ }^{28}$ as well as between PEMCS and white-matter integrity in young adulthood. ${ }^{29}$ Together, these findings suggest significant consequences of PEMCS on the offspring brain. But, in the absence of longitudinal data from birth onward, and owing to the difficulty of ruling out all possible confounders of cigarette smoking during pregnancy in human studies, the directionality and causality of these effects can be established only in experimental studies in animal models. In such studies, pregnant dams are exposed to nicotine, the primary constituent in tobacco smoke. Roy and Sabherwal ${ }^{30}$ illustrated that longterm exposure to gestational nicotine decreased the thickness of the somatosensory cortex among offspring at all ages examined, namely, at postnatal days 10, 20, and 40, which corresponds to adolescence. Further histological analysis suggested that the nicotine-induced reduction in cortical thickness was related to reductions in dendritic complexity and soma size but not to a loss of cells. ${ }^{30}$ Later studies suggest that prenatal exposure to nicotine induces cytoplasmic vacuolation, enlargement of intercellular spaces, and an increase in the number of apoptotic cells. ${ }^{31}$ Primate studies have provided supportive evidence by illustrating that tobacco exposure during pregnancy can lead to decreases in cell size, increases in cell-packing density, and a reduction in cell number, especially in the temporal cortex. ${ }^{32}$ Although these studies have evaluated the effects of nicotine, it is important to acknowledge the potential role of other major constituents in tobacco smoke, some of which have been shown to interact with nicotine. ${ }^{33,34}$
Altogether, we suggest that the effect of maternal smoking during pregnancy on the developing brain and, in particular, the OFC, influences the likelihood of experimenting with drugs during adolescence. For a large number of exposed adolescents who have not experimented with any substances, OFC thickness is comparable to that of nonexposed adolescents with the same drug-free history (Figure). These findings further support the hypothesis that only exposed individuals with a thinner OFC are more susceptible to increased drug experimentation.

\section{DRUG-TAKING BEHAVIOR AND OFC DYSFUNCTION}

The most extensive effects of PEMCS on cortical thinning were observed in the OFC, as reported previously. ${ }^{8}$ It is possible that PEMCS interferes with OFC development, leading to functional consequences, namely, higher probability of drug experimentation. The OFC has been directly linked to impulsivity and cueassociated reward processing in nonhuman primates. ${ }^{12}$ In rats, prenatal exposure to nicotine increases the dose of cocaine necessary to maintain its self-administration, thus suggesting an increased reward threshold. ${ }^{6}$ In humans, several imaging studies of adults with drug addiction identified changes in cerebral blood flow and glucose metabolism in the OFC. ${ }^{9,13,35}$ Higher cerebral blood flow in the OFC during the performance of the Iowa Gambling Task was observed in participants addicted to cocaine compared with control participants, suggesting greater OFC engagement in the anticipation of reward among these individuals. ${ }^{9}$ During protracted withdrawal, however, adults with drug addiction exhibit lower glucose metabolism in the OFC than do controls, as measured by positron emission tomography. ${ }^{35}$ This finding is consistent with the results of structural magnetic resonance imaging studies that have found lower volumes of gray matter in the OFC and prefrontal cortices in adults with drug addiction, compared with controls. ${ }^{11,36}$ Our finding of a negative relationship between OFC thickness and drug experimentation could be related to either higher impulsivity or higher reward threshold among exposed adolescents with progressively lower OFC thickness.

\section{EXPERIENCE-INDUCED PLASTICITY}

We found that increasing OFC thickness correlates with the number of drugs tried only among nonexposed adolescents with the Val/Val genotype, which is known for its more efficient activity-dependent release of BDNF; this was not the case among adolescents with the Met/Val or Met/Met genotypes. This suggests that cortical thickness among nonexposed adolescents reflects a gene (BDNF) and environment (drug use) interaction. The primary substance use variable in our analyses was the number of different drugs tried by adolescents during their lifetime. It is likely that this is a good predictor of the overall likelihood of drug-taking behavior, as shown by the positive correlation between the number of different drugs tried in the lifetime and the number of days of 
marijuana smoking in the last 30 days; marijuana was the most commonly used illicit drug in our population (total sample: $R^{2}=0.33 ; F_{1,86}=42.3 ; P<.001 ;$ and MRI sample: $\left.R^{2}=0.24 ; F_{1,59}=18.5 ; P<.001\right)$.

Drugs of abuse are known to have a significant effect on the structure and function of the brain. ${ }^{37}$ Although the mechanisms remain unknown, a number of molecular pathways have been proposed. ${ }^{37}$ Neurotrophic factors represent one such candidate system ${ }^{37,38}$ known to influence dendritic complexity, as well as cell size and survival, axonal outgrowth, and synaptic plasticity. Through a series of recent experiments, drug-induced changes in BDNF release and its consequences on structural plasticity have been demonstrated. ${ }^{39}$ BDNF expression in the frontal cortex, compared with other brain regions, appears to be particularly susceptible to drug use. ${ }^{40}$ Moreover, the effects appear to be drug specific. Although exposure to stimulants has been shown to increase dendritic complexity and the number of dendritic spines in the prefrontal cortex, opiate exposure appears to exert the opposite effect. ${ }^{37}$ In our population, the illegal substances most commonly used by adolescents were marijuana, stimulants, and psychedelic drugs.

Mice with forebrain-restricted knockout of BDNF exhibit cortical thinning of the somatosensory and visual cortices; this effect is attributed to a decrease in dendritic arborization and cell size but not necessarily to a loss in cell number. ${ }^{41}$ In humans, the Val to Met substitution has been shown to alter the prodomain of the BDNF protein, which inhibits its packaging into secretory granules. ${ }^{42}$ This change ultimately decreases activitydependent release of BDNF in Met carriers. ${ }^{42}$ Structural differences in the brain of healthy individuals with the different Val/66/Met BDNF genotype include alterations in the volume of gray matter in the hippocampus, amygdala, and thickness of the prefrontal cortex. ${ }^{43,44}$

We conclude that the effect of an adolescent's drugtaking experience on brain structure could be modified by genetic makeup, with BDNF as a critical player. Future longitudinal studies evaluating the structure of the brain before, during, and after the onset of drug use are necessary to explore these findings further. This geneenvironment interaction was present, however, only in adolescents not exposed to maternal cigarette smoking in utero. This raises an important methodological consideration for future studies and an interesting scientific question: Is it possible that PEMCS renders BDNF less effective regardless of the genotype?

\section{A COMMON LINK}

In experimental animals, the effect of prenatal exposure to nicotine and the BDNF knockout are remarkably similar: both decrease cortical thickness and reduce dendritic branching. In humans, serum BDNF levels are diminished in long-term smokers but return to normal levels following cessation of cigarette smoking, thus suggesting a negative effect of cigarette smoke on BDNF expression. ${ }^{45}$ Kenny et $\mathrm{al}^{5}$ found that short- and long-term nicotine exposure can influence BDNF expression (messenger RNA) in the brain of the adult rat. Maternal smoking dur- ing pregnancy is associated with a higher rate of DNA methylation among offspring. ${ }^{46}$ We speculate that PEMCS is associated with an epigenetic modification of the BDNF gene that, in turn, decreases the likelihood of its expression in response to neural activity. Such a modification may represent a mechanism for PEMCS-induced interference with cortical development and explain the lack of moderating effect of the BDNF genotype on the relationship between OFC thickness and the number of different drugs tried by exposed adolescents. We cannot rule out the possibility that the lack of differences in the relationship between OFC thickness and the number of drugs tried is owing to other biological or methodological issues. But, the similarity of the exposed and nonexposed groups in the number of $\mathrm{Val} / \mathrm{Val}$ homozygotes and Met carriers and in age and sex, as well as the fact that they all come from the same white founder population, argues against the latter.

\section{STRENGTHS AND LIMITATIONS}

The main strengths of the Saguenay Youth Study cohort include the matching of nonexposed with exposed adolescents by maternal educational level, a detailed assessment of adolescents' family environment and cognitive abilities, as well as the relatively high cultural and genetic homogeneity of the region. ${ }^{15}$ One of the main limitations of the study is the fact that PEMCS was determined by maternal reports, which may be subject to recall bias. As described elsewhere ${ }^{15}$ however, we verified most maternal reports using medical records completed during pregnancy. Furthermore, the observed differences in birth weight for exposed vs nonexposed adolescents ${ }^{15}$ also support the validity of the retrospective assessment of maternal smoking during pregnancy in our sample. Finally, it has been suggested that underreporting of smoking may be higher at the time of pregnancy because of the immediate influence of the stigma associated with smoking while pregnant. ${ }^{47}$

\section{CONCLUSION}

First, we report that PEMCS is associated with higher substance use during adolescence. Second, we demonstrate a moderating effect of PEMCS on the relationship between the thickness of the OFC and drug experimentation. Finally, we document a moderating effect of $B D N F$ genotype on the same structure-function relationship in adolescents not exposed to prenatal maternal cigarette smoking. We propose 2 separate mechanisms that may mediate drug-taking behavior in our adolescent population. First, given the existing literature on animal models, we speculate that PEMCS induces changes in OFC thickness and, in turn, influences the likelihood of drug experimentation during adolescence. Second, in the nonexposed population, we suggest that age acts as a significant predictor of substance use, through maturational changes in sensitivity to drug reward or through enhanced access to drugs during adolescence. Finally, among nonexposed adolescents, we propose that BDNF genotype modulates

(REPRINTED) ARCH GEN PSYCHIATRY/VOL 66 (NO. 11), NOV 2009 WWW.ARCHGENPSYCHIATRY.COM 
experience-driven plasticity related to drug use, which then affects OFC thickness. Longitudinal studies in humans and experimental animals are needed to provide further evidence to support these findings.

Submitted for publication: December 18, 2008; final revision received March 20, 2009; accepted March 24, 2009. Correspondence: Tomáš Paus, MD, PhD, Brain and Body Centre, University of Nottingham, University Park, Nottingham NG7 2RD, United Kingdom (thomas.paus @nottingham.ac.uk).

Financial Disclosure: None reported.

Funding/Support: The Saguenay Youth Study is funded by the Canadian Institutes of Health Research (Drs Paus and Pausova), Heart and Stroke Foundation of Quebec (Dr Pausova), and the Canadian Foundation for Innovation (Dr Pausova).

Additional Information: The eTables and eAppendix are available at http://www.archgenpsychiatry.com.

Additional Contributions: We thank the following individuals for their contributions in acquiring and analyzing the data: Chantale Belleau, MPs; Mélanie Drolet, MA; Catherine Harvey, MPs; Stéphane Jean, PhD (candidate); Hélène Simard, BA; Mélanie Tremblay, MA; Patrick Vachon, PhD (candidate); the ÉCOBES (Groupe d'Étude des Conditions de vie et des Besoins de la population) team (Nadine Arbour, MÉd; Julie Auclair, MSc; Marie-Ėve Blackburn, PhD [candidate]; Marie-Ève Bouchard, DEC; Annie Houde, BA; Catherine Lavoie, DEC); Julie Bérubé, MSc; and Rosanne Aleong, PhD. We also thank Jean Mathieu, MD, for the medical follow-up of participants in whom we detected any medically relevant abnormalities. We thank Manon Bernard, BSc, for designing and managing our database.

\section{REFERENCES}

1. DiFranza JR, Lew RA. Effect of maternal cigarette smoking on pregnancy complications and sudden infant death syndrome. J Fam Pract. 1995;40(4):385394.

2. Huijbregts SC, Séguin JR, Zoccolillo M, Boivin M, Tremblay RE. Maternal prenatal smoking, parental antisocial behavior, and early childhood physical aggression. Dev Psychopathol. 2008;20(2):437-453.

3. Ernst M, Moolchan ET, Robinson ML. Behavioral and neural consequences of prenatal exposure to nicotine. J Am Acad Child Adolesc Psychiatry. 2001;40 (6):630-641.

4. Weissman MM, Warner V, Wickramaratne PJ, Kandel DB. Maternal smoking during pregnancy and psychopathology in offspring followed to adulthood. J Am Acad Child Adolesc Psychiatry. 1999;38(7):892-899.

5. Kenny PJ, File SE, Rattray M. Acute nicotine decreases, and chronic nicotine increases the expression of brain-derived neurotrophic factor mRNA in rat hippocampus. Brain Res Mol Brain Res. 2000;85(1-2):234-238.

6. Franke RM, Park M, Belluzzi JD, Leslie FM. Prenatal nicotine exposure changes natural and drug-induced reinforcement in adolescent male rats. Eur $J$ Neurosci. 2008;27(11):2952-2961.

7. Perry DC, Dávila-García MI, Stockmeier CA, Kellar KJ. Increased nicotinic receptors in brains from smokers: membrane binding and autoradiography studies. J Pharmacol Exp Ther. 1999;289(3):1545-1552.

8. Toro R, Leonard G, Lerner JV, Lerner RM, Perron M, Pike GB, Richer L, Veillette S, Pausova Z, Paus T. Prenatal exposure to maternal cigarette smoking and the adolescent cerebral cortex. Neuropsychopharmacology. 2008;33(5):1019-1027.

9. Bolla KI, Eldreth DA, London ED, Kiehl KA, Mouratidis M, Contoreggi C, Matochik JA, Kurian V, Cadet JL, Kimes AS, Funderburk FR, Ernst M. Orbitofrontal cortex dysfunction in abstinent cocaine abusers performing a decision-making task. Neuroimage. 2003;19(3):1085-1094.

10. Everitt BJ, Hutcheson DM, Ersche KD, Pelloux Y, Dalley JW, Robbins TW. The orbital prefrontal cortex and drug addiction in laboratory animals and humans [published online December 18, 2007]. Ann N Y Acad Sci. 2007;1121:576597. doi:10.1196/annals.1401.02.

11. Franklin TR, Acton PD, Maldjian JA, Gray JD, Croft JR, Dackis CA, O'Brien CP Childress AR. Decreased gray matter concentration in the insular, orbitofrontal, cingulate, and temporal cortices of cocaine patients. Biol Psychiatry. 2002; 51(2):134-142.

12. Rolls ET. The orbitofrontal cortex and reward. Cereb Cortex. 2000;10(3):284-294.

13. Goldstein RZ, Volkow ND. Drug addiction and its underlying neurobiological basis: neuroimaging evidence for the involvement of the frontal cortex. Am J Psychiatry. 2002;159(10):1642-1652.

14. Schultz W, Tremblay L, Hollerman JR. Reward processing in primate orbitofrontal cortex and basal ganglia. Cereb Cortex. 2000;10(3):272-284.

15. Pausova Z, Paus T, Abrahamowicz M, Almerigi J, Arbour N, Bernard M, Gaudet D, Hanzalek P, Hamet P, Evans AC, Kramer M, Laberge L, Leal SM, Leonard G, Lerner J, Lerner RM, Mathieu J, Perron M, Pike B, Pitiot A, Richer L, Séguin JR, Syme C, Toro R, Tremblay RE, Veillette S, Watkins K. Genes, maternal smoking, and the offspring brain and body during adolescence: design of the Saguenay Youth Study. Hum Brain Mapp. 2007;28(6):502-518.

16. Fischl B, Dale AM. Measuring the thickness of the human cerebral cortex from magnetic resonance images. Proc Natl Acad Sci U S A. 2000;97(20):1105011055.

17. Desikan RS, Ségonne F, Fischl B, Quinn BT, Dickerson BC, Blacker D, Buckner RL, Dale AM, Maguire RP, Hyman BT, Albert MS, Killiany RJ. An automated labeling system for subdividing the human cerebral cortex on MRI scans into gyral based regions of interest. Neuroimage. 2006;31(3):968-980. doi:10.1016/j.neuroimage .2006.01.021.

18. Chiavaras MM, LeGoualher G, Evans A, Petrides M. Three-dimensional probabilistic atlas of the human orbitofrontal sulci in standardized stereotaxic space. Neuroimage. 2001;13(3):479-496.

19. Lohoff FW, Sander T, Ferraro TN, Dahl JP, Gallinat J, Berrettini WH. Confirmation of association between the Val66Met polymorphism in the brain-derived neurotrophic factor (BDNF) gene and bipolar I disorder. Am J Med Genet B Neuropsychiatr Genet. 2005;139B(1):51-53.

20. Lucas CP, Zhang H, Fisher PW, Shaffer D, Regier DA, Narrow WE, Bourdon K, Dulcan MK, Canino G, Rubio-Stipec M, Lahey BB, Friman P. The DISC Predictive Scales (DPS): efficiently screening for diagnoses. J Am Acad Child Adolesc Psychiatry. 2001;40(4):443-449.

21. McReynolds LS, Wasserman GA, Fisher P, Lucas CP. Diagnostic screening with incarcerated youths: comparing the DPS and Voice DISC. Crim Justice Behav. 2007;34(6):830-845.

22. Zoccolillo M, Vitaro F, Tremblay RE. Problem drug and alcohol use in a community sample of adolescents. J Am Acad Child Adolesc Psychiatry. 1999;38(7): 900-907.

23. Lerner RM, Lerner JV, Almerigi J, Theokas C, Phelps E, Gestsdottir S, Naudeau S, Jelicic H, Alberts A, Ma L, Smith L, Bobek D, Simpson I, Christiansen E, von Eye A. Positive youth development, participation in community youth development programs and contributions of fifth grade adolescents: findings from the first wave of the 4-H Study of Positive Youth Development. J Early Adolesc. 2005; 25(1):17-71.

24. Séguin JR, Freeston MH, Tarabulsy GM, Zoccolillo M, Tremblay RE, Carbonneau $R$. Développement des comportements anxieux au préscolaire: de nouvelles mesures et influences familiales. Presented at: Québec Mental Health Network Annual Meeting; June 2, 2000; Montréal, Quebec.

25. Steinberg L, Monahan KC. Age differences in resistance to peer influence. Dev Psychol. 2007;43(6):1531-1543.

26. Raudenbush SW, Bryk AS. Hierarchical Linear Models: Applications and Data Analysis Methods. 2nd ed. Newbury Park, CA: Sage Publications; 2002.

27. Hox J. Multilevel Analysis: Techniques and Applications. London, England: Lawrence Erlbaum Associates; 2002.

28. Rivkin MJ, Davis PE, Lemaster JL, Cabral HJ, Warfield SK, Mulkern RV, Robson $\mathrm{CD}$, Rose-Jacobs R, Frank DA. Volumetric MRI study of brain in children with intrauterine exposure to cocaine, alcohol, tobacco, and marijuana. Pediatrics. 2008; 121(4):741-750.

29. Jacobsen LK, Picciotto MR, Heath CJ, Frost SJ, Tsou KA, Dwan RA, Jackowski MP, Constable RT, Mencl WE. Prenatal and adolescent exposure to tobacco smoke modulates the development of white matter microstructure. J Neurosci. 2007; 27(49):13491-13498.

30. Roy TS, Sabherwal U. Effects of prenatal nicotine exposure on the morphogenesis of somatosensory cortex. Neurotoxicol Teratol. 1994;16(4):411-421.

31. Roy TS, Sabherwal U. Effects of gestational nicotine exposure on hippocampal morphology. Neurotoxicol Teratol. 1998;20(4):465-473.

32. Slotkin TA, Pinkerton KE, Seidler FJ. Perinatal environmental tobacco smoke exposure in rhesus monkeys: critical periods and regional selectivity for effects on brain cell development and lipid peroxidation. Environ Health Perspect. 2006; $114(1): 34-39$. 
33. Fowler JS, Volkow ND, Wang GJ, Pappas N, Logan J, MacGregor R, Alexoff D, Shea C, Schlyer D, Wolf AP, Warner D, Zezulkova I, Cilento R. Inhibition of monoamine oxidase B in the brains of smokers. Nature. 1996;379(6567):733-736.

34. Franke RM, Belluzzi JD, Leslie FM. Gestational exposure to nicotine and monoamine oxidase inhibitors influences cocaine-induced locomotion in adolescent rats. Psychopharmacology (Berl). 2007;195(1):117-124.

35. Volkow ND, Fowler JS. Addiction, a disease of compulsion and drive: involvement of the orbitofrontal cortex. Cereb Cortex. 2000;10(3):318-325.

36. Makris N, Gasic GP, Kennedy DN, Hodge SM, Kaiser JR, Lee MJ, Kim BW, Blood AJ, Evins AE, Seidman LJ, Iosifescu DV, Lee S, Baxter C, Perlis RH, Smoller JW, Fava M, Breiter HC. Cortical thickness abnormalities in cocaine addiction: a reflection of both drug use and a pre-existing disposition to drug abuse? Neuron. 2008;60(1):174-188.

37. Russo SJ, Mazei-Robison MS, Ables JL, Nestler EJ. Neurotrophic factors and structural plasticity in addiction. Neuropharmacology. 2009;56(suppl 1): 73-82.

38. Bolaños CA, Nestler EJ. Neurotrophic mechanisms in drug addiction. Neuromolecular Med. 2004;5(1):69-83.

39. Pierce RC, Bari AA. The role of neurotrophic factors in psychostimulant-induced behavioral and neuronal plasticity. Rev Neurosci. 2001;12(2):95-110.

40. Le Foll B, Diaz J, Sokoloff P. A single cocaine exposure increases BDNF and D3 receptor expression: implications for drug-conditioning. Neuroreport. 2005; 16(2):175-178.

41. Gorski JA, Zeiler SR, Tamowski S, Jones KR. Brain-derived neurotrophic factor is required for the maintenance of cortical dendrites. J Neurosci. 2003;23(17): 6856-6865.

42. Bath KG Lee FS. Variant $B D N F($ Val66Met) impact on brain structure and function. Cogn Affect Behav Neurosci. 2006:6(1):79-85.

43. Schofield PR, Williams LM, Paul RH, Gatt JM, Brown K, Luty A, Cooper N, Grieve S, Dobson-Stone C, Morris C, Kuan SA, Gordon E. Disturbances in selective information processing associated with the BDNFVal66Met polymorphism: evidence from cognition, the P300 and fronto-hippocampal systems [published online September 16, 2008]. Biol Psychol. 2009;80(2):176-188. doi:10.1016/j biopsycho.2008.09.001.

44. Sublette ME, Baca-Garcia E, Parsey RV, Oquendo MA, Rodrigues SM, Galfalvy H, Huang YY, Arango V, Mann JJ. Effect of BDNFval66met polymorphism on agerelated amygdala volume changes in healthy subjects. Prog Neuropsychopharmacol Biol Psychiatry. 2008;32(7):1652-1655. doi:10.1016/j.pnpbp.2008.06 009

45. Kim TS, Kim DJ, Lee H, Kim YK. Increased plasma brain-derived neurotrophic factor levels in chronic smokers following unaided smoking cessation. Neurosci Lett. 2007;423(1):53-57.

46. Terry MB, Ferris JS, Pilsner R, Flom JD, Tehranifar P, Santella RM, Gamble MV, Susser E. Genomic DNA methylation among women in a multiethnic New York City birth cohort. Cancer Epidemiol Biomarkers Prev. 2008;17(9):2306-2310.

47. Huizink AC, Mulder EJ. Maternal smoking, drinking, or cannabis use during pregnancy and neurobehavioral and cognitive functioning in human offspring. Neurosci Biobehav Rev. 2006;30(1):24-41. 